\title{
Productivity Slowdown, Exhausted Opportunities and the Power of Human Ingenuity-Schumpeter Meets Georgescu-Roegen
}

\author{
Andreas Pyka *, Kristina Bogner ${ }^{(D)}$ and Sophie Urmetzer $\mathbb{D}$ \\ Institute for Economics, University of Hohenheim, 70599 Stuttgart, Germany \\ * Correspondence: a.pyka@uni-hohenheim.de
}

Received: 30 May 2019; Accepted: 21 June 2019; Published: 26 June 2019

\begin{abstract}
Western economies nowadays are confronted with a predicted productivity slowdown resulting in diminishing rates of economic growth. While some scholars see these developments as an indication of the approaching end of growth due to fully exploited technological opportunities, this article contends that the possibilities for radical, paradigm changing innovations are far from being exploited. Building on contributions from Schumpeter and Georgescu-Roegen, we argue that the human capacity to expand technological and intellectual frontiers must not be underestimated. In a selective retrospect, our narrative identifies and describes four historical incidents reflecting different perceptions of the power of the human mind. It synthesizes the mentioned economists' viewpoints with the effects of these incidents to reproduce the intellectual roots of the recently developed concept of Dedicated Innovation Systems (DIS). We conclude that traditional macro-level indicators are not suitable to capture transformation processes, which is why we propose to interpret growth indicators and the alleged productivity slowdown quite differently. We argue that human ingenuity and transformation processes dedicated to sustainability will open up new opportunity spaces, thereby combining an increase in economic welfare and social justice with a reduction of negative environmental impact.
\end{abstract}

Keywords: economic growth; economic development; Schumpeter; Georgescu-Roegen; productivity slowdown; knowledge; human ingenuity; transformation; qualitative change; Dedicated Innovation System (DIS)

\section{Introduction}

For 200 years, Western economies have generated impressive economic growth, leading to improved living conditions, prolonged life expectancies and increasing wealth. During the last 50 years, however, awareness is rising that this trend cannot last forever and is currently approaching its limits. Interestingly, the admonishers for the end of economic growth come from two opposing intellectual camps. On the one hand, recently, (macro-)economists see clear evidence for the approaching end of human ingenuity. They interpret the stagnation or decrease of (GDP or TFP) growth rates in Western economies as an obvious symptom of the full exploitation of technological opportunities $[1,2]$ leading to a situation in which new ideas and knowledge are getting increasingly hard to find [3]. This Gordon dilemma allegedly indicates that economic growth in its current form "may not be a continuous long-run process that lasts forever" [1] (p. 3), but rather productivity and economic growth are already slowing down and probably going to stop in the not too far future. On the other hand, environmentalists, sustainability scientists and capitalism sceptics argue on the basis of finite natural resources [4], planetary boundaries [5] and the neglect of true costs for natural capital [6]. While varying significantly in explaining the exact reasons for this inevitable end of growth, these two lines of 
argument tend to agree on the basic assumption that humans are part of the problem (by their greed and their intellectual capacity) rather than part of the solution (by their culture and their ingenuity). While we fully acknowledge that (a) natural resources are limited and (b) conventional parameters of economic growth are on the decline, we suggest interpreting the signals fundamentally differently. More precisely, we do, albeit not blindly, confide in human creativity to create a desirable future in which we achieve the UN's sustainable development goals (SDG) [7]. In this context, we trust that a further increase in prosperity is indeed possible while at the same time considerably alleviating environmental and social pressures.

Based on a reinterpretation of historic, current and future developments in Western Economies, our paper aims at sketching an alternative potential pathway directed to achieve sustainability. Our vision builds on the cognition that "(e)conomics is an artefact of human society" [8] (p. 183) instead of following the law of nature. Not only does the human brain generate economic progress, it equally defines "the rules of the game and establish(es) its mores" [8] (p. 183) and is thereby also able to re-create the future. By reconciling the Schumpeterian trust in human ingenuity [9-11] with Georgescu-Roegen's plea for normativity $[12,13]$, we propose a more optimistic scenario for future trajectories. We argue that a transformation of production and consumption systems in the face of the current social and environmental problems caused by these systems is not only imperative from a normative perspective. What is more, we expect the trajectories towards the SDGs to open up a radically new opportunity space allowing for qualitative development instead of mere quantitative economic growth.

In our paper, we aim to explain why we consider the currently discussed scenarios on economic growth too pessimistic and why we perceive human ingenuity and future innovative activity not only as part of the problem, but as part of the solution for the social, economic, and environmental challenges. To reach this aim, we explore the following research questions::

- Building on theoretical considerations, can we approve the Gordon dilemma and the projected scenarios on future economic progress?

- How can the power of human ingenuity and different types of knowledge be used for confronting the pessimistic future projections?

To answer these research questions, we apply a rather narrative analytical approach. The selective choice of sources and anecdotal evidence we base our arguments on, are products of innumerable conversations, teaching experience, and scientific debates. The countless references to the issue of economic growth made by the two congenial economists Schumpeter and Georgescu-Roegen are summarized and discussed in an admittedly subjective manner. Notwithstanding the limitations of such methodological approach, we deem our deliberations an important contribution to the scientific debate and an imperative first step towards improving the interpretation and future appraisal of the alleged productivity slowdown.

Our article is structured as follows: Section 2 sets the scene by shedding some light on economic growth and the productivity slowdown. In Section 3, we will present theoretical groundings of Schumpeter and Georgescu-Roegen concerning economic growth and development and guide our line of argument by presenting three propositions on human ingenuity. In Section 4, we will enlist four historical incidents reflecting certain points of departure of the transformative power of the human mind. These incidents serve to explain why we see the need for dedication in transformation processes. The concluding Section 5 summarizes our paper and proposes some avenues for further research.

\section{Exhausted Opportunities and Productivity Slowdown}

The longest time in human history has been characterized by an imposing lack of economic growth. For thousands of years, living standards were remarkably stagnant and countries showed stable and very low-income levels. Only within the last two centuries, this changed radically (with some regions exhibiting completely different growth patterns than others). 
In economic theory, these phenomena have been intensely discussed by economists such as, for instance, Adam Smith [14], Thomas Malthus [15], David Ricardo [16], Joseph Alois Schumpeter [9], Robert Solow [17], Trevor Swan [18], Richard Nelson and Sidney Winter [19], Paul Romer [20], Robert Lucas [21], and many more. Economic growth has traditionally been attributed to either an increase or different use of the production factors land, capital, and labor, or to technological improvements [22]. In this context, scholars identify productivity increases as the main drivers of growth $[2,23]$. This conjecture has been backed up by, among others, an acceleration in the growth rates of the gross domestic product (GDP) per capita and of the total factor productivity (TFP).

While we are nowadays quite accustomed to increasing wealth and growing GDP rates, it is an indisputable fact that, from a historical perspective, economic prosperity and lasting economic growth are a very recent (and probably unique) achievement of humanity. It goes without saying that this short period affected our living conditions remarkably. While "(s)ome measures of progress are subjective" [2] (p. 5), there are many examples of positive developments connected to economic growth, such as a lengthened life expectancy, decrease of infant mortality and hygienic improvements, to name just a few [2]. Indeed, economic growth has been one of the most powerful instruments in creating prosperity, reducing poverty, increasing the quality of life, and advancing human development in Western economies [23]. For a very long period of time, scholars and policy makers seemingly assumed that the tremendous growth we experienced within the last two centuries will and has to continue unrestrained, eventually infinitely repeating the same growth patterns.

However, this brief period might be currently approaching its end. Especially during the last fifty years, awareness is rising that economic growth cannot last forever and is currently approaching its limits [1]. Recognizing that economic growth is far from being steady or continuous, Gordon projects that it will not provide for a continuous economic advancement century after century [2]. It is more likely that phases with remarkable economic growth are followed by phases with slower growth (or no growth at all). The mere observation of traditional growth determinants, such as the (real) per capita GDP growth rates, the TFP growth rates or the labor productivity growth rates, suggests that in the U.S. and other Western countries "growth since the 1970s has been simultaneously dazzling and disappointing" [2] (p. 2).

Naturally, the question arises of why we are observing these patterns. One possible explanation can be found in the work of Bloom et al. [3] and their application of Solow's [24] growth accounting to the production of new ideas. According to idea-based growth models, the stylized view shows that economic growth is the product of research productivity multiplied by the number of researchers [3]. The logic is that economic growth occurs due to an increase in research productivity and the number of researchers (or the growth of one multiplier offsetting the decline in the other). Since U.S. economic growth rates have been relatively stable or declining while the number of researchers increased over the last decades, Bloom and colleagues [3] conclude that "research productivity is declining sharply" [3] (p. 2). They show that the relative stable growth rate the U.S. economy showed in the past has only been possible due to the strong increase in the number of researchers, which so far offset the decline in individual research productivity. In line with other scholars [1,2,25,26], Bloom and colleagues conjecture that this reduction in research productivity simply results from a lack of new ideas. In many fields, ideas are getting increasingly hard to find and much more research effort is needed to produce new economic growth.

Bloom et al.'s [3] findings strongly support what Robert Gordon found when he asked: "Is U.S. economic growth over?" [1]. Gordon, however, even takes the argument one step further. In his book "The Rise and Fall of American Growth" [2], Robert Gordon establishes why the tremendous growth Western economies experienced between the 1870s and the 1970s must be considered an outcome of what he calls 'the special century' - the exception rather than the rule. What makes that century so special is that " $(\mathrm{t})$ he flood of inventions that followed the Civil War utterly transformed life" [2] (p. 4). During that time, human genius made inventions that cannot be repeated, leaving following generations with the impression that all great inventions have already been made [2]. As examples, 
Gordon brings in the conversion from rural to urban life, the speed of travel, the temperature of rooms, and the near-elimination of brute-force manual labor [1] (p. 15). He considers U.S. economy's future growth not only to be facing the problem of declining research productivity, but to crown it all, of an almost fully exploited opportunity space. In the face of aging societies, large public debts, growing income inequalities, and reduced qualification returns from increasing investment in education, we are currently facing the Gordon dilemma. His core contention is that the productivity growth rates of the past are no longer reproducible due to almost fully exploited opportunity sets. We are facing a productivity slowdown.

\section{Reply to the Gordon Dilemma: Three Propositions}

\subsection{Qualitative Change and Human Ingenuity}

Since Simon Kutznets [27], researchers distinguish economic growth, modern economic growth, and economic development. Economic growth in this context is simply expressed by an increase of the GDP over time, whereas modern economic growth implies GDP growth per capita. Economic development, in contrast to mere (modern) economic growth, captures not only quantitative growth but also qualitative changes. Such changes can be observed, for instance, in structural changes of entire industries. One very prominent observer of this qualitative dimension was Joseph Schumpeter [9-11]. According to him, economic development is a dynamic evolutionary process, characterized by the introduction of creative new combinations, the destruction of the hitherto customary, and subsequent qualitative change [9-11]. "Capitalism ( ... ) is by nature a form or method of economic change and not only never is but never can be stationary. ( ... ) The fundamental impulse that sets and keeps the capitalist engine in motion comes from the new consumers' goods, the new methods of production or transportation, the new markets, the new forms of industrial organization that capitalist enterprise creates. (...) (It is) industrial mutation that incessantly revolutionizes the economic structure from within, incessantly destroying the old one, incessantly creating a new one." [11] (pp. 82-83). Economic development in Schumpeter's understanding can be described as "the disruption of the regular circular flow caused by the introduction of novelties" [28] (p. 4), either by the entrepreneur or by R\&D departments in large companies leading to qualitative change [28]. According to Hanusch and Pyka [28], qualitative change in this context affects all levels of the economy, not only by creating structural changes but also by removing constraints and allowing for development under new circumstances. These qualitative changes, however, do not appear regularly in time. This is why periods of smoother development are followed by periods of radical change. Such unequal distribution of endogenously generated innovations in time leads to cyclical patterns of economic development [10].

According to Schumpeter, it is the introduction of new combinations (in the sense of innovations) that drives economic evolution in the first place [10]. What is more, the generated innovations "are responsible for overcoming previous limiting conditions and-as in economic reality, everything has an end-setting new ones." [28] (p. 1). This is, in fact, central to Schumpeterian theory on economic progress: the potential of innovation to defeat the limits of the feasible whenever an exhaustion of opportunities is close. To prove his point, Schumpeter was one of the first scholars who investigated the relationship between developments on the micro level (as entrepreneurial decisions and the introduction of innovations), developments on the meso level (as industry dynamics) and large-scale qualitative changes on the macro level [28]. As the force on the micro level, Schumpeter prides the entrepreneur and his ingenuity in being decisive for economic development and transformations of economies. The Schumpeterian entrepreneur (in later works also large R\&D departments [11]) can be described as Schumpeter's hero, as the actor that "kicks off economic development" [28] (p. 4). Quite in contrast to the static neoclassical representative agent, the Schumpeterian entrepreneur is ambitious and his unending ingenuity will inevitably "disturb the prevailing order and constitute the kernel of unbalanced developments" [28] (p. 23). With this new framing of large-scale qualitative changes provoked 
by individual innovative economic actors, Schumpeter prepared the ground for what subsequent evolutionary economists later coined as shifts of technological [29] or socio-technical [30,31] paradigms.

Following this line of argumentation, the observed productivity slowdown proves nothing more than a large-scale qualitative change or, in other words, the transition between two economic paradigms. The Schumpeterian new combinations and creative destruction will prove Gordon's dilemma vain by creating a whole new opportunity set, resulting in powerful qualitative change instead of mere quantitative growth. This also opposes the contention that all great inventions have already been made [1,2]. For one of the very characteristics of true novelties is that they seem impossible and indeed unimaginable when regarded from what we know today [8]. Human ingenuity is an inexhaustible resource, which constantly generates progress by pushing the limits of the possible.

These considerations based on Schumpeter's theories lead to our first proposition:

Proposition 1: Trust in human ingenuity and the power of qualitative change. This involves adopting an unprecedented perspective enabling the creation of new and hitherto unimaginable opportunity sets.

\subsection{The Downside of Human Ingenuity}

Without doubt Joseph Schumpeter revolutionized economics within the last 100 years with his masterpieces on "The Theory of Economic Development" [9] and on "Capitalism, Socialism and Democracy" [11]. However, seen from our perspective today, Schumpeter reveals a very narrow understanding of economic affairs by admitting that non-economic forces acting upon economic phenomena cannot and need not be taken into account in economic analyses. "We have (...) accomplished what we, as economists, are capable of in the case in question, and we must give place to other disciplines. If, on the other hand, the causal factor is itself economic in nature, we must continue our explanatory efforts until we ground upon a non-economic bottom." [9] (pp. 4-5). Today, the economy's dependency on and embeddedness in all kinds of non-economic systems (natural, social, cultural, ... ) is widely recognized - albeit mostly in theory. This deficiency to internalize non-economic forces has been addressed by Schumpeter's fellow student Nicholas Georgescu-Roegen by applying the second law of thermodynamics, the entropy law, on economic development $[12,13]$. Georgescu-Roegen defined Schumpeter's work as the seeds which inspired his later work and turned him into an economist [32]. By establishing the connection between biophysics and economics, Georgescu-Roegen provided scientific reasons for why qualitative change and irreversibility constitute omnipresent phenomena in the economic process [12]. What is more, some researchers even pride Georgescu-Roegen's work and especially his acknowledgement of the intimate and inseparable connection between economic activity and ecological processes for leading him "one important step beyond his teacher" [33] (p. 263). Within his guild, Georgescu-Roegen was a pioneer in acknowledging that nature is not a subsystem of the economy, but rather the economy can be seen as a "generally constrained and vulnerable" [33] (p. 266) subsystem of nature, showing the "co-evolutionary nature of the development of economy and the environment" [33] (p. 266). Through his reference to the entropy law, Georgescu-Roegen not only supported Schumpeter's introspective claim of the non-stationarity of the economic process and the irreversibility of economic (and other) activities. In addition, and more important, not only is the occurrence of qualitative change inevitable but "according to Georgescu-Roegen's analysis, environmental and natural resource issues are, in fact, intimately and inseparably connected to any economic activity". [33] (p. 263). Therefore, with his seminal works, and especially his magnum opus, the entropy law, Georgescu-Roegen established environmental economics and founded the discipline of bioeconomics $[12,13,34]$.

Owed to his strong focus on the interdependency of economics and the environment, Georgescu-Roegen felt the necessity to introduce a certain kind of regulative mechanism in favor of the environment into economic thinking. By acknowledging the fact that all resources are finite and susceptible to degradation when put to use in economic activity, he concluded that only by adding a 
normative perspective to future economic activities we would be able to account for the long-term interests of the planet and the people. Otherwise, our planet would inevitably collapse in the future. With this entropy pessimism and his critique of the anomaly of the market allocation mechanisms or the ecological market failure, he pointed to the fact that "the market mechanism by itself results in resources being consumed in higher amounts by the earlier generations, that is, faster than they should be" [13] (p. 375). According to him, the market fails to solve this intergenerational allocation problem, as it is unable to regard future generations, leading to the "dictatorship of the present over the future" [13] (p. 375). This Georgescu-Roegenian entropy pessimism seems to be in stark contrast to Schumpeter's technology and innovation optimism.

Resulting from these considerations, we formulate the following second proposition:

Proposition 2: The human ingenuity with its unlimited character has led to great inventions as well as to undesirable uncontrollable outcomes. Innovation is not per se desirable and thus needs to be accompanied by normative considerations.

\subsection{Reconciling Schumpeter and Georgescu-Roegen}

At first sight, the serene stance taken by Schumpeter (Section 3.1) and the dire projections made by Georgescu-Roegen (Section 3.2) seem to severely contradict each other. While sharing the same understanding of qualitative economic change and sharing the skepticism against neo-classical steady state considerations, the two progenitors come to rather contrasting conclusions concerning the role and effect of technology, innovation and human ingenuity. While Schumpeter clearly expects the human mind to ensure an endless increase in prosperity (without any consideration of possible negative effects), Georgescu-Roegen builds on the same human mind to postulate the necessity to define rules and values for the economy. The human genius has brought us far. But if it is not curtailed by normative boundaries it will inevitably steer the dynamics of economic and ecological development towards disaster $[12,35]$. What unites the two in their respective lines of thought is the undaunted centrality of the human brilliancy. And while for them, as for many other economists before and after, entrepreneurial spirit and ingenuity seems to be hard to reconcile with normative considerations and ethical values, we propose to consider them both as products of the human mind. We consequently treat them as two of the same kind: different types of knowledge [36]. It is this knowledge-centered perspective of both scholars that inspires a new approach to normative innovation scholarship. We argue that both academics offer valid and valuable arguments that help to rebut the alleged productivity slowdown projected by Gordon and Bloom:

Schumpeter's understanding of evolutionary processes, the role of creative destruction and qualitative changes, driven by entrepreneurial activity, quite impressively shows, why he would have highly disagreed with Gordon's, Bloom's and other colleagues' projection of a fully exploited opportunity space. The potency of human ingenuity and the resulting entrepreneurial activity currently revolutionizes the economic structure from within, destroying the old one and thereby creating a whole new one. Therefore, applying Schumpeter's line of reasoning, the productivity slowdown we are observing by looking at the traditional data and indicators simply results from the fact that these indicators fail in measuring and displaying evolutionary processes as qualitative change or paradigm shifts.

Georgescu-Roegen would have argued in a relatively similar manner, albeit offering different conclusions. We are indeed in the process of qualitative change. So even in Georgescu-Roegen's line of argument, it is neither the full exploitation of opportunities nor the fact that all great inventions have already been made, which lead to productivity slowdown and a potential end of growth. Quite the contrary: Similar to Schumpeter, Georgescu-Roegen places such confidence in human ingenuity, that he even ascribes self-destruction to the human mind. If at all, and if finite resources are put into use the way they have been the last two centuries, the end of growth will be the result of a collapse 
in the carrying capacity of our planet. In a sense, human ingenuity is much more likely creating too many opportunities and therefore has to be directed or dedicated to commonly defined goals. The human brain is able to create new opportunity sets, which offer hitherto unimaginable possibilities. Nonetheless, in contrast to Schumpeter, Georgescu-Roegen points to the fact that the outcomes can be positive as well as very negative.

By acknowledging the evolution of economic systems and the underlying qualitative changes, both scholars explain why we do not face a fully exploited opportunity set as the reason for a productivity slowdown and a possible end of growth. Putting the power of the human genius at the center and based on the reconciliation of Schumpeter's and Georgescu-Roegen's perceptions, we formulate the following third proposition:

Proposition 3: Schumpeter's human ingenuity and Georgescu-Roegen's normative considerations are both inherently knowledge-based. Their ideas enable us to reinterpret the productivity indicators in a way that makes better sense of the past while informing responsible decisions for the future.

\section{On the Power of Knowledge and its Mandate to Transform}

As any other scholar, Schumpeter and Georgescu-Roegen were children of their times when they developed their theories. Political, cultural, and technological developments shaped the questions that scientists sought to provide answers to [37]. For instance, while environmental degradation and resource scarcity were not an issue between the 1910s and 1940s when Schumpeter published his main pieces, this radically changed in the 1960s and 1970s when environmental concerns climbed up in the political agendas of western economies inspiring Georgescu-Roegen to reconcile economic and ecological systems. Against the backdrop of societal developments since then, a further refinement of innovation theory towards a directed and at the same time creative conceptualization of knowledge-driven progress seems logical. Acknowledging that history matters in interpreting economic indicators we are asked as economists to react to such external influences and adjust our theories, methods, assumptions, and interpretations. Just as technological breakthroughs provoked changes in measuring and forecasting progress, knowledge-related novelties must be expected to upset traditional ways of appreciation and projection of human development. Since the days of Schumpeter and Georgescu-Roegen, we can identify four incisive knowledge-related historical events happening in Western countries. We do admit that many other important events happened since then and the ones presented here display incidents that primarily influenced Western economies' development. Nevertheless, we argue that our selection illustrates quite boldly, what we consider to epitomize the evolution of the economically relevant knowledge-base during the last 60 years. More precisely, we ascribe each of these events to a certain effect on the assumptions, aspirations, and values of Western innovation trajectories. In the following, we will first describe these effects in detail using them in a second step as a basis for our modern innovation system framework, termed dedicated innovation systems (DIS) [38]. The interpretation of the knowledge-related historical incidents provides an explanation of the observed drop in productivity indicators, while the DIS concept offers the theoretical underpinnings for reacting to these observations.

\subsection{Historical Developments: Four Knowledge-Related Effects}

\subsubsection{Transcending Insurmountable Barriers: The Apollo Effect}

The back then unimaginable success of the Apollo moon-travel missions in the 1960s [39] fully confirmed Schumpeter's trust in the power of human ingenuity and fueled enthusiasm for the unending possibilities created by the human mind: Technological development due to high targets and evermore advanced specialist knowledge proved to transcend hitherto insurmountable barriers. At that time, innovation was all about exploiting and expanding the technological potential for the collective 
improvement of economic growth. This growth created tremendous GDP per capita increases, which led to unprecedented mass production and expanded consumption in Western economies. The family expenditure of the average U.S. worker had been redirected from food, rent, fuel, and light to other consumption goods and leisure. Production and consumption and the underlying patterns changed tremendously. The idea of mass production was complemented by the idea of product differentiation driven by various sorts of IT applications and their pervasive diffusion. The economic growth created by the human genius was expected to automatically drive social well-being; ecological considerations did not play a role. The guiding principle back then was 'bigger, higher, faster' [40]. During that time, the perks of exploiting the fruits of human ingenuity to the fullest in combination with the technology enthusiasm overlaid the fact that the unlimited human ingenuity and knowledge, which created economic growth is not only unlimited in its ability to create but also in its ability to demolish. It had simply been overlooked that products of human ingenuity, i.e., innovation, might not always be per se desirable and that economic growth might come at (social or environmental) costs, such as increasing inequality or environmental degradation. This enthusiasm for technological progress provoked a policy-driven very distinguished focus on mere techno-economic knowledge in Western economies. Techno-economic knowledge can be described as the knowledge necessary to create economic value [36]. It is also this kind of knowledge Schumpeter and most other economists focused on. Techno-economic knowledge, in contrast to other types of knowledge, does not contain any direction or dedication. It simply answers the question what is possible and necessary from a technological and economic point of view and can be successful at the market [41]. Still today, economists and politicians most of the time actually only think of techno-economic knowledge when making general statements on knowledge. This strong focus on only one fraction of knowledge neglected other perceptions of the human mind, notably contextual insights, values, and norms. This overemphasis of economically relevant knowledge at the expense of other types of knowledge by economists and politicians alike has been highly criticized, lately. To improve the conceptualization of knowledge in DIS, the notion of dedicated knowledge has been coined recently, encompassing besides techno-economic knowledge also systems knowledge, normative knowledge, and transformative knowledge. [36]. One of the first opponents to this overemphasis of techno-economic knowledge was Nicolas Georgescu-Roegen who, albeit using a different terminology, stressed the importance of considering non-economic expertise in innovation processes, too.

\subsubsection{Limits to Growth: The Club of Rome Effect}

Georgescu-Roegen's notion of ecological limits and intergenerational injustice resonated well with a whole new school of thought that emerged at the same time the Apollo-missions were flying to the moon. Founded in 1968, the Club of Rome gained sudden prominence through its seminal publication "The Limits to Growth" [4]. For the first time, the unshakeable trust in constant economic growth was publicly and prominently questioned by offering a very new interpretation of human activity in, responsibility for and dependency from natural ecosystems. The economic system was no longer seen as separate entity subject to positive or negative externalities. Economic outcomes were finally understood to be both responsible for and responsive to developments within the surrounding ecosystem. It was the spirit of that time that Georgescu-Roegen breathed when he wrote down his considerations on entropy and bioeconomics.

In current times of climate change and dwindling biodiversity at ever-faster rates, the Club of Rome's problem framing seems to be more valid than ever. As a consequence, current growth-centered capitalistic logic must be either abandoned [42] or normatively restrained [6,8]. The former stance was taken by growth criticists who claimed that the limited carrying capacity of our planet will inevitably set a physical boundary to growth patterns. In this context, different streams of scholarship developed concepts such as Zero-Growth [43,44], Degrowth [12,35,44], or Post-Growth as strategies at hand to address current social, economic, and ecological limitations and problems $[8,40]$. Proponents of such theories commonly agree that human existence and action are the core problem of our times 
and must be curbed in one way or the other. At the same time, their projections are based on an entirely linear notion of economic development thus denying the potential of qualitative change. A different perspective was taken by the United Nations when founding the World Commission on Environment and Development (WCED) in 1983 as a response to the crisis of capitalism. This group of experts contributed to the debate by proposing that growth indeed can continue if subjected to certain principles. For this, they revived the actually quite dated notion of sustainability-the self-evident principle of forestry not to harvest more than can be reproduced by nature. Based on this idea, their report "Our Common Future" [45] formed the next milestone in dealing with undesirable developments by introducing a new standard for future progress: not economic growth or economic development, but sustainable development, i.e., "development that meets the needs of the present without compromising the ability of future generations to meet their own needs" [45]. This powerful concept was adopted by policy, business, research, and civil society alike and still shapes the debate the most recent advancement being the global agreement on pursuing the Sustainable Development Goals (SDG's) [7]. These developments clearly indicate a change in thinking of larger parts of our society. In contrast to the strong and sole focus on and positive perception of mere techno-economic knowledge in the past, other types of knowledge gained ground. Capitalist critics and end of growth admonishers started to build up and make use of systems knowledge and normative knowledge. Systems knowledge in this context is the descriptive, interdisciplinary understanding of relevant systems and the dynamics and interactions between these biological, economic, and social systems [36]. Normative thinking in this context is the collectively developed knowledge about desired system states to formulate systemic goals [36]. The consideration of these two types of knowledge in economics is rooted in the works of the Club of Rome has been further developed since.

\subsubsection{Distributing the Burden: The Mass University Effect}

Besides the Apollo Effect and the Club of Rome Effect, we identified a third effect, namely the Mass University Effect, as another knowledge-related event decisive for the immense developments after the 1960s. In 1961, Karl Jaspers coined the notion of a mass university for the first time [46,47]. The immense investment and reforms of universities since the end of the 1960s were responsible for a tremendous growth of the knowledge base in larger parts of the society in the following decades. Education of the masses was identified as being the driver of economic progress [48] since "better education yields higher individual income and contributes towards the construction of social capital and long-term economic growth." [48]. Driven by success stories of the past and the technology and innovation optimism of that time, especially engineering skills and management competences widely spread out throughout the society. The number of students, as well as the number of universities of applied sciences, grew impressively over the last 100 years [49]. Western societies became more and more academic and the idea of education for the elites had been replaced by the idea of education of the people (the masses). The (still present) spirit of that time demanded an opening up of knowledge for the masses and an exploitation of the collective knowledge of the society. The increase in (higher) education reflected the prevailing Zeitgeist, highlighting the chance of a growing knowledge base in general, and more distributed competencies in particular. Analogous to mass production in combination with product differentiation (Apollo Effect), the increasing mass production of knowledge in the society was complemented by an intensified differentiation of competencies and increase of experts' knowledge through growing rates of higher education. Until today, this development does not only allow for an increase in techno-economic knowledge and opportunities for (technological) progress and innovation. Pluralistic governance needs to build upon educated people, exploiting the collective knowledge of the society, capitalizing on all types of knowledge and human ingenuity. Therefore, the Mass University Effect can be suspected having led to an ever-increasing hunger for education, and with that, the proficiency to participate in the design of our future. 


\subsubsection{Beyond Economic Reasoning: The Summer of Love Effect and the \#FridaysForFuture Effect}

It comes as no surprise that this education of the masses (Mass University Effect) initiated not only the capability for beginning to understand the economic, social, and environmental problems of that time, but also the increasing justified claim of participation, pluralistic governance, and alternative ways of life. Skepticism against the prevailing consumerist values, a general mistrust in governments, and pacifist tendencies developed during the early 1960s, gave rise to growing discontent in certain parts of North American society. This culminated in the gathering of thousands of 'hippies' during the Summer of Love in 1967 in various cities of the continent. The Summer of Love became a synonym for the peaceful riots propagating an alternative way of life, pursuing a kind of 'cultural utopia' with no room for hypocrisy, bureaucracy, violence, and social inequality [50,51]. Albeit rather short in duration and relatively local in occurrence, this revolution became a symbol for the power of social movements that advocate values rather distinct from purely economic logic. A handful of individuals who dared to point to systemic fallacies and idle values managed to incite a movement against common perceptions. If unifying a critical amount of people, such new kind of thinking based on systems knowledge and normative knowledge can gain prominence and eventually even influence decisions made on business or political levels. A very recent example for the recovered power of such movements is the phenomenon of the \#FridaysForFuture gatherings [52]. Starting with a quite personal agenda of a Swedish teenager concerned about climate change, the protests quickly spread around the world attracting more and more pupils every week. The results of the European elections in 2019 are even said to be heavily influenced by the impressions that the demonstrating pupils left in voters' minds [53]. This movement demonstrated the power and potency of the human mind and the different types of knowledge even more impressively than the Summer of Love movements. Despite its local starting point, the perks of digitalization and social media allowed a spreading and exchange of initially rather dispersed knowledge, indicating an overcoming of geographical boundaries, an even clearer understanding of the interconnectedness of systems, and a relatively broad consensus about (at least) inacceptable states of the future.

\subsection{From the Mico Level to the Macro Level: Knowledge in Dedicated Innovation Systems (DIS)}

The four knowledge-related historical events presented above quite impressively show how micro-level changes in the knowledge space can and will affect meso- and macro-level events and vice versa. Within the last 60 years, the centrality of knowledge in economic processes has increased tremendously [54,55]. Starting with the prominent role of knowledge ascribed through Schumpeterian economics, the tremendous growth of the knowledge base resulted in impressive economic growth (with all its positive and negative effects). To those growth criticists who see humans to be part of the problem (by their greed and their intellectual capacity) we respond by offering a theory that harnesses this very capacity for finding the solution.

We fully agree that human ingenuity in the past has led to undesirable and uncontrollable outcomes. However, especially due to the increase and diffusion of different kinds of knowledge, as systems knowledge and normative knowledge, we also fully confide in the power of human ingenuity to create, diffuse, and use transformative knowledge. This kind of knowledge will enable mankind to become truly transformative by creating new opportunities and offering innovative solutions to our problems, thereby overcoming the negative impacts on the macro level. We do not share the pessimistic future perception of the growth criticists $[8,12,35,40,44,56]$, nor the unrealistic optimism of eco-modernism [57]. On the one hand, we confide in the perks of prosperity, on the other we do not believe in eco-friendly techno-fixes as a large-scale solution. To master a system-wide deep transformation, it is not enough to cure symptoms. Instead, knowledge creation and collective innovation process at the micro level have to be governed towards a transformation on the macro level. This is only possible, if we change our focus from fostering mere techno-economic knowledge towards the creation and diffusion of dedicated knowledge [36]. The latter comprises an understanding of the dynamics and processes of ecological and social systems (systems knowledge), an awareness 
of the desired states of a system (normative knowledge), as well as knowledge, which builds on systems and normative knowledge to inform the development of strategies for changing systems towards the desired state (transformative knowledge) [36]. Systems thinking teaches us that one of the few possibilities to influence outcomes at the macro level is reconsidering the way we use our knowledge in the systems we are embedded [58]. One framework supporting this focus on knowledge in combination with normative considerations is the framework of dedicated innovation system (DIS) recently coined by Pyka [38,59].

DIS "explicitly go beyond technological innovation and economic growth and allow for paradigmatic change towards sustainability: They are "dedicated" to foster the joint search for transformative innovations. In other words, the proposed conception of DIS implies that the predominant focus of innovation systems on economic competitiveness needs to step back behind the global societies' imperative of sustainability." [38] (p. 3). This dedication will help empowering the actors within the system in creating and diffusing different kinds of knowledge, affecting micro-level events such as entrepreneurial decision. These micro-level events will lead to creative destruction and meso-level events, i.e., industry dynamics as the creation of new industries and the death of traditional unsustainable industries. On the macro level, dedicated innovation systems allow for evolutionary economic development and paradigm shifts towards sustainability. This does not happen overnight, nor does is follow a linear transformation path. We have to keep in mind that DIS "are characterized by their dynamic and co-evolutionary nature and thus are enormously complex." [38] (p. 3).

Summing up, inspired by Schumpeter's considerations of economic development and the relationships between different operational levels many decades ago, we call for a transformation on the macro level, driven by dedicated changes on the micro level. Sustainable development can only be achieved by the exploitation of many different, but equally important, kinds of knowledge. This knowledge and the resulting dedicated entrepreneurial decisions offer the creation and utilization of promising new technological opportunities along a sustainable trajectory. On the meso level, this will provoke step-wise structural changes in industries characterized by a co-existence of unsustainable established and sustainable future industries for many years. On the macro level, these developments will prompt the evolution of a new techno-economic paradigm [37] or a new socio-technical system [60], allowing for qualitative development and quantitative growth. This Schumpeterian understanding of evolutionary economic development also quite impressively shows, why the traditional data and indicators (mainly measuring quantitative changes at the macro level) will not allow us to measure, understand and guide transformation processes. The same problem was already quite nicely shown by the Solow computer paradox [61,62], which describes the phenomenon in which "(y)ou can see the computer age everywhere but in the productivity statistics" [62], showing the discrepancy between investment in IT and meso level output measures.

\subsection{Meso-Level Measurements: On the Measurement of Qualitative Change}

Keeping this macro-level focus of traditional indicators in mind and considering the three presented propositions in Section 3 quite naturally leads to a different interpretation compared to Gordon and fellows: The quantitative data and indicators economists analyze traditionally (GDP, TFP, labor productivity, ... ) indeed indicate a productivity slowdown and potentially the end of quantitative growth on the macro level. However, "(i)n industrial societies, quantitative growth cannot be the indicator of economic growth; only qualitative growth can be the correct indicator" [63] (p. 9). Traditional indicators do not account for this qualitative growth. They do not account for micro- or meso level events. Therefore, they do not allow for assessing whether or not the observed productivity slowdown results from exhausted opportunities on the micro or meso level.

In line with many other scholars, we advise against relying too much on traditional indicators, especially for measuring and understanding transformation processes and for directing policies fostering the transformation towards sustainability. For one thing, traditional data and indicators do not (sufficiently) account for other factors affecting growth, such as human capital, political institutions 
structural change and entrepreneurial behavior $[64,65]$. What is more, traditional indicators as GDP or TFP also fail in measuring, displaying and explaining other important aspects, such as inequality, quality of life, environmental impacts, and many other welfare values. "Despite this new consensus that broad socioeconomic progress should be prioritized much more strongly in economic policy, GDP growth statistics continue to be the primary way national economic performance is tracked by governments and reported in the media" [66]. This still is the case even though nowadays, there exists many different well-calculated indicators, using relevant data besides the mere production capacity of a country.

Therefore, we argue that we are only observing a productivity slowdown, to the extent that the traditional indicators are not able to represent qualitative economic development and structural change (in the sense of Schumpeter or Georgescu-Roegen) but only (parts of) mere quantitative growth on the macro level. We understand that collecting data and deducing general statements is "hampered by the desire to ensure indicators are simple, easily accessible, comparable across nations, and cheap to acquire and compute." [67]. However, we must account for the fact that "these requirements do not reflect the complex and often messy realities of innovation, let alone capture whether the innovation has negative consequences ... " [67]. By exclusively relying on traditional quantitative data and indicators we fall into the trap of a modern Solow computer paradox [61,62]. This is why indicators as the GDP, TFP or labor productivity in isolation can neither show nor explain, let alone guide, paradigm shifts and transformation processes.

Acknowledging Schumpeter's considerations regarding the relationship between different levels helps to understand why only data and indicators of events on the micro or the meso level will allow us deeper insights in economic development and transformation processes towards sustainability at the macro level. Already 20 years ago, Donella Meadows gave an impressive overview over indicators and information systems for sustainable development [68], thereby already giving some suggestions of how to better measure such qualitative changes as well as to incorporate normative considerations. However, much research effort is still needed in this context, since the indicators we consider relevant and necessary simply do not exist, yet. Based on other authors' suggestions and our understanding of the visibility of structural change at different levels, we had a first, very superficial non-comprehensive, glance at data. By looking at, e.g., entrepreneurial behavior, employment, and structural change in the labor market as well as changing consumer preferences, we wanted to get a first impression of changes in our production and consumption patterns. A first interpretation of this data suggests, that we are already in an early stage of a transformational process. The productivity slowdown we are facing must actually be read as indicating a paradigm shift in the hitherto rather detrimental production and consumption patterns. Regarding, e.g., entrepreneurial activities and behavior, we see a strong movement. In 2018, every fourth start-up in Germany is green [69]. More than $50 \%$ of these green start-ups have a digital business model [69], indicating the special role digitalization can play in fostering the transformation towards sustainability and contributing to improve resource-efficiency. The fact that these green start-ups do not focus on one branch or technology in particular, but operate in many diverse technological fields [69] emphasizes the overall role this movement towards sustainability might play within the whole economy. Looking at employment and structural changes in the labor market shows a similar picture. There is a general trend towards greener employment. Green start-ups created more than one million jobs within the last 10 years [69]. What is more, green companies have a higher rate of female employees as well as there are more female entrepreneurs of green companies than of non-green companies [69], showing a better incorporation of all parts of society i.e., diversity and with it creativity compared to incumbents. In addition, not only is there an increase in green companies, but employment in relation to the transformation towards sustainability increases as well. Another possible indicator for an already initiated transformation towards sustainability are changing consumer preferences and consumption decisions. In their study on green products in Germany [70], the German Environmental Office found that consumer preferences changed towards more sustainable 
consumption. In some fields, e.g., energy efficient home appliances, green products already reached a market share above 50\% and the market potential is far from being fully unlocked [70].

Summarizing, only adequate metrics can and have to direct better policies. We have to be careful when poorly determined indicators become political targets and drive political action of governments. Neither can the traditional indicators display paradigm shifts or transformation endeavors, nor should they be used to direct policies for the transformation (towards sustainability). We criticize that these indicators fail in adequately directing policies, especially towards SDGs. Therefore, it comes as no surprise that only two out of the 17 indicators the UN defines to track the achievements of the targets of SDG 8 (Promote sustained, inclusive and sustainable economic growth, full and productive employment and decent work for all), are tracked by GDP growth. Our paper shows that the transformation at the macro level is driven by knowledge-related events on the micro level and their effects on the meso level. Therefore, we see a need for collecting and looking at different and more future-oriented data and indicators at the micro and the meso level to show, understand and guide the already initiated transformation processes. As this is a rather narrative conceptual paper based on anecdotal evidence, the identification and correct measurement of relevant data and indicators is a first suggestion for future research. While it has been quite straightforward to identify the inadequacy of traditional indicators to measure sustainable development, the identification and collection of more relevant data is more challenging. What is more, we point to the fact that we have to accept that indicators that are simple, easily accessible, comparable across nations, and cheap to acquire and compute, reflect a rather myopic approach, which simply does not account for the complex reality.

\section{Summary and Conclusions}

Since the industrial revolution, Western economies' growth has been an outstanding success story, which has led to improved living conditions, prolonged life expectancy, and increasing wealth. Therefore, countries like the U.S. and the Western European economies nowadays are accustomed to ever-increasing wealth. During the last 50 years, however, awareness is rising that this trend cannot last forever and is currently approaching its limits. Economists as Robert Gordon or Nicholas Bloom and colleagues are cautioning Western economies of exhausted opportunities and declining productivity rates, resulting in the Gordon dilemma of productivity slowdown and a potential end of growth. At the same time, capitalist criticists also forecast an end of growth due to the limited carrying capacity of our planet.

Combining Joseph Schumpeter's and Nicolas Georgescu-Roegen's ideas, together with a theoretical analysis of important knowledge-related events during the last 60 years, we explain why we consider the above scenarios on economic growth too pessimistic and why we perceive human ingenuity and future innovative activity as part of the solution and not only part of the problem for the social, economic, and environmental challenges we are facing.

Already 100 years ago, Joseph Schumpeter taught us that economic development is an evolutionary process characterized by creative destruction and qualitative change. The human mind creates new knowledge and new combinations, which revolutionize the economic structure from within, destroying the old one, creating a new one, leading to cyclical movements and paradigm shifts. Inspired by his (and other scientists') understanding of economic processes, we cannot approve Gordon's dilemma and his projected scenarios on future economic progress. While we admit that the traditional data and indicators imply a productivity slowdown, we heavily disagree that this slowdown results from a fully exploited opportunity space, i.e., that all great inventions have already been made. We argue that the alleged slowdown only results from the fact that the traditional indicators are not able to represent qualitative economic development. The productivity slowdown we are facing must actually be read as indicating a paradigm shift in the hitherto rather detrimental production and consumption patterns. What is more, we consider that human ingenuity together with this paradigm shift opens up radically new opportunity spaces and allows for new great inventions triggering future economic development and prosperity. 
However, we show that human ingenuity can only fully exploit its positive and transformative potential, if we adapt a new understanding of different kinds of knowledge and promote these. Even though past and current knowledge-related events showed a heading in the right direction, we have to use the current momentum for directing the so far unlimited and undirected human ingenuity. To our understanding, this will only be possible in an adjusted modern innovation system framework, called dedicated innovation systems (DIS) [38]. The DIS concept not only provides explanations of the observed drop in productivity indicators but, at the same time, it offers the theoretical underpinnings for reacting to these observations and guiding the already initiated paradigm shift. Within DIS, collective innovation processes ground on regularly debated and redefined normative assumptions and respect the requirements of $t$ responsible innovation. The resulting dedicated paradigm shifts or transformations towards sustainability will not happen overnight. We must be prepared to tolerate a co-existence of unsustainable established and newly emerging sustainable industries.

We conclude that traditional indicators are not suitable for capturing transformation processes, which is why we propose to interpret growth indicators and the alleged productivity slowdown quite differently. Instead, we emphasize the role of human ingenuity and argue that transformation processes dedicated to sustainability will open up new opportunity spaces, thereby combining an increase in economic welfare and social justice with a reduction of negative environmental impacts.

In our paper we apply a rather narrative analytical approach, thereby arguing based on selective choice of sources and anecdotal evidence. Therefore, the transferability of our results is limited for several reasons. First, the strong focus of our analysis on Western Economies neglects a large and increasingly relevant part of the global economy. The productivity slowdown we are facing and the indicators we are observing are only valid in countries such as the U.S. or Europe. Other countries and economies, such as the BRICS, show different developments and therefore could likely lead to differing conclusions. As Kim and Heshmati [63] (p. 7) put it: “( .. ) from an economic growth perspective, the agricultural economy which decelerates and the industrial economy which accelerates have different characteristics; in other words, they are different organisms that possess different genes in the context of economic growth". In addition, as economic development is always strongly influenced by past events, the conclusions of the presented knowledge-related events are not easily transferable to other cultural or socio-economic contexts. In addition, we are only analysing the productivity slowdown, the indicators and the allegedly exhausted opportunities from a theoretical point of view. Future research avenues therefore should investigate the development of, e.g., the BRICS, and analyse whether our arguments also hold for these economies. Even more important, we need to collect better data and construct suitable indicators for measuring and showing qualitative changes as paradigm shifts and transformations, which at that point goes beyond the scope of our paper. This is why future research is required to gain deeper insights in meso-level indicators.

Summing up, we emphasize human ingenuity for exploring and conquering so far unseen opportunity spaces, creating and shaping our future world. However, in the light of the current economic, ecological and social problems, which resulted from past economic growth processes and the overemphasis of the economic dimension, we believe that human ingenuity can only exploit its full potential in creating sustainable development if it is directed by a respective dedication.

Author Contributions: A.P., K.B. and S.U. contributed equally as lead authors. All authors read carefully and approved the final version of the manuscript.

Funding: This paper was presented as a keynote speech of SOItmC 2019, and the publishing fee was generously supported by SOItmC.

Conflicts of Interest: The authors declare no conflict of interest. 


\section{References}

1. Gordon, R.J. Is US Economic Growth Over? Faltering Innovation Confronts the Six Headwinds. NBER Working Paper Series. 2012. Available online: https://www.nber.org/papers/w18315.pdf (accessed on 24 June 2019).

2. Gordon, R.J. The rise and fall of American growth: The US Standard of Living Since the Civil War; Princeton University Press: Princeton, NJ, USA, 2017.

3. Bloom, N.; Jones, C.I.; van Reenen, J.; Webb, M. Are Ideas Getting Harder to Find? NBER Working Paper Series. 2017. Available online: https://www.nber.org/papers/w23782.pdf (accessed on 24 June 2019).

4. Meadows, D.H.; Randers, J.; Behrens III, W.W. The Limits to Growth: A Report to the Club of Rome (1972). Available online: http://www.ask-force.org/web/Global-Warming/Meadows-Limits-to-Growth-Short-1972. pdf (accessed on 24 June 2019).

5. Steffen, W.; Richardson, K.; Rockström, J.; Cornell, S.E.; Fetzer, I.; Bennett, E.M.; Biggs, R.; Carpenter, S.R.; Vries, W.D.; Wit, C.A.D.; et al. Planetary boundaries: Guiding human development on a changing planet. Science 2015, 347, 1259855. [CrossRef] [PubMed]

6. Hawken, P.; Lovins, A.B.; Hunter Lovins, L. Natural Capitalism; Earthscan by Routledge: New York, NY, USA, 2013; ISBN 9781315065755.

7. United Nations. Transforming our World: The 2030 Agenda for Sustainable Development. 2015. Available online: https://sustainabledevelopment.un.org/content/documents/21252030\%20Agenda\%20for\% 20Sustainable\%20Development\%20web.pdf (accessed on 18 September 2018).

8. Jackson, T. Prosperity without Growth; Earthscan by Routledge: New York, NY, USA, 2016; ISBN 9781315677453.

9. Schumpeter, J.A. The Theory of Economic Development: An Inquiry into Profits, Capital, Credit, Interest, and the Business Cycle; Routledge, Taylor \& Francis: New York, NY, USA, 1934.

10. Schumpeter, J.A. Business Cycles; McGraw-Hill New York: New York, NY, USA, 1939.

11. Schumpeter, J.A. Capitalism. Socialism and Democracy; Routledge: New York, NY, USA, 1943.

12. Georgescu-Roegen, N. The Entropy Law and the Economic Process; Harvard University Press: Cambridge, MA, USA, 1971; ISBN 9780674281646.

13. Georgescu-Roegen, N. Energy and Economic Myths. South. Econ. J. 1975, 41, 347-381. [CrossRef]

14. Smith, A. An Inquiry into the Nature and Causes of the Wealth of Nations; Cosimo: New York, NY, USA, 1776.

15. Malthus, T.R. An Essay on the Principle of Population; Pickering \& Chatto Publishers: London, UK, 1798.

16. Ricardo, D. The Principles of Political Economy and Taxation. 1817. Available online: https://socialsciences. mcmaster.ca/econ/ugcm/3113/ricardo/Principles.pdf (accessed on 24 June 2019).

17. Solow, R.M. A contribution to the theory of economic growth. Q. J. Econ. 1956, 70, 65-94. [CrossRef]

18. Swan, T.W. Economic growth and capital accumulation. Econ. Rec. 1956, 32, 334-361. [CrossRef]

19. Nelson, R.R.; Winter, S.G. An Evolutionary Theory of Economic Change; Harvard University Press: Cambridge, UK, 1982.

20. Romer, P.M. Increasing returns and long-run growth. J. Polit. Econ. 1986, 94, 1002-1037. [CrossRef]

21. Lucas, R.E., Jr. On the mechanics of economic development. J. Monet. econ. 1988, 22, 3-42. [CrossRef]

22. Alfano, M.R. Economic Growth. In Encyclopedia of Law and Economics; Backhaus, J., Ed.; Springer New York: New York, NY, USA, 2014.

23. Roser, M. Economic Growth. Available online: https://ourworldindata.org/economic-growth (accessed on 24 May 2019).

24. Solow, R.M. Technical Change and the Aggregate Production Function. Rev. Econ. Stat. 1957, $39,312$. [CrossRef]

25. Griliches, Z. Productivity, RED, and the Data Constraint. RED and Productivity: The Econometric Evidence; University of Chicago Press: Chicago, IL, USA, 1998; pp. 347-374.

26. Jones, B.F. The burden of knowledge and the "death of the renaissance man": Is innovation getting harder? Rev. Econ. Stud. 2009, 76, 283-317. [CrossRef]

27. Kuznets, S. Modern Economic Growth: Findings and Reflections. Am. Econ. Rev. 1973, 63, 247-258.

28. Hanusch, H.; Pyka, A. Elgar Companion to Neo-Schumpeterian Economics; Edward Elgar Publishing: Cheltenham, UK, 2007; ISBN 1847207014.

29. Dosi, G. Technological paradigms and technological trajectories: A suggested interpretation of the determinants and directions of technical change. Res. Policy 1982, 11, 147-162. [CrossRef] 
30. Freeman, C. Schumpeter's business cycles and techno-economic paradigms. In Techno-Economic Paradigms: Essays in Honour of Carlota Perez; Drechsler, W., Kattel, R., Reinert, E.S., Eds.; Anthem Press: London, UK, 2009; pp. 125-144.

31. Perez, C. Technological revolutions and techno-economic paradigms. Camb. J. Econ. 2010, 34, $185-202$. [CrossRef]

32. Bobulescu, R. The making of a Schumpeterian economist: Nicholas Georgescu-Roegen. Eur. J. Hist. Econ. Thought 2012, 19, 625-651. [CrossRef]

33. Heinzel, C. Schumpeter and Georgescu-Roegen on the foundations of an evolutionary analysis. Camb. J. Econ. 2013, 37, 251-271. [CrossRef]

34. Gowdy, J.; Mesner, S. The Evolution of Georgescu-Roegen's Bioeconomics. Rev. Soc. Econ. 1998, 56, 136-156. [CrossRef]

35. Latouche, S. Farewell to Growth; Polity Press: Cambridge, UK, 2009.

36. Urmetzer, S.; Schlaile, M.P.; Bogner, K.; Mueller, M.; Pyka, A. Exploring the Dedicated Knowledge Base of a Transformation towards a Sustainable Bioeconomy. Sustainability 2018, 10, 1694. [CrossRef]

37. Perez, C. Technological revolutions, paradigm shifts and socio-institutional change. In Globalization, Economic Development and Inequality: An Alternative Perspective; Reinert, E.S., Ed.; Edward Elgar Publishing: Cheltenham, UK, 2004; pp. 217-242.

38. Pyka, A. Dedicated innovation systems to support the transformation towards sustainability: creating income opportunities and employment in the knowledge-based digital bioeconomy. J. Open Innov. Technol. Mark. Complex. 2017, 3, 27. [CrossRef]

39. Wood, B. Apollo Program Summary Report. 1975. Available online: http://www.hq.nasa.gov/alsj/APSR-JSC09423.pdf (accessed on 24 June 2019).

40. Jackson, T. Prosperity without Growth. Foundations for the Economy of Tomorrow, 2nd ed.; Routledge: Oxon, UK, 2017.

41. Bogner, K. United We Stand, Divided We Fall_Essays on Knowledge and Its Diffusion in Innovation Networks; University of Hohenheim: Stuttgart, Germany, 2019.

42. Smith, R. Green Capitalism: The God that Failed; College Publications: London, UK, 2015.

43. Daly, H.E. Steady-State Economics, 2nd ed.; Island Press: Washington, DC, USA, 1991; ISBN 155963071X.

44. Kerschner, C. Economic de-growth vs. steady-state economy. J. Clean. Prod. 2010, 18, 544-551. [CrossRef]

45. WCED. Our Common Future: Report of the World Commission on Environment and Development. 1987. Available online: https://sustainabledevelopment.un.org/content/documents/5987our-common-future.pdf (accessed on 23 May 2019).

46. Burch, R. Jaspers' Concept of the University. Can. J. High. Edu. 1976, 6, 13-41.

47. Jaspers, K.; Rossmann, K. Die Idee der Universität; Springer: Berlin, Germany, 1961.

48. Roser, M.; Ortiz-Ospina, E. Global Rise of Education. Available online: https://ourworldindata.org/globalrise-of-education (accessed on 24 June 2019).

49. Roser, M.; Ortiz-Ospina, E. Tertiary Education. Available online: https://ourworldindata.org/tertiaryeducation (accessed on 24 June 2019).

50. Davis, F. Why all of us may be hippies someday. Society 1967, 5, 10-18. [CrossRef]

51. Spann, E.K. Democracy's Children: The Young Rebels of the 1960s and the Power of Ideals; Rowman \& Littlefield Publishers: Wilmington, CA, USA, 2003.

52. Fridays for Future. \#FridaysForFuture. Available online: https://fridaysforfuture.org/ (accessed on 24 June 2019).

53. Bell, B. European Elections 2019: Political Climate Mmay Boost Greens. Available online: https://www.bbc. com/news/world-europe-48280135 (accessed on 25 June 2019).

54. Foray, D.; Lundvall, B.-Å. The knowledge-based economy: from the economics of knowledge to the learning economy. In The Economic Impact of Knowledge; Neef, D., Siesfeld, A.G., Cefola, J., Eds.; Butterworth-Heinemann: Boston, MA, USA, 1998; pp. 115-121.

55. Lundvall, B.-Å. Knowledge management in the learning economy. Danish Research Unit for Industrial Dynamics Working Paper. 2006. Available online: https://ideas.repec.org/p/aal/abbswp/06-06.html (accessed on 24 June 2019).

56. Daly, H.E. Beyond Growth: The Economics of Sustainable Development; Beacon Press: Boston, MA, USA, 1996; ISBN 9780807047095. 
57. Asafu-Adjaye, J.; Blomquist, L.; Brand, S.; Brook, B.W.; Defries, R.; Ellis, E.; Forem, C.; Keit, D.; Lew, M.; Lyna, M.; et al. An Ecomodernist Manifesto. 2015. Available online: https://static1.squarespace.com/static/5515d9f9e4b04d5c3198b7bb/t/552d37bbe4b07a7dd69fcdbb/ 1429026747046/An+Ecomodernist+Manifesto.pdf (accessed on 14 June 2019).

58. Abson, D.J.; Fischer, J.; Leventon, J.; Newig, J.; Schomerus, T.; Vilsmaier, U.; von Wehrden, H.; Abernethy, P.; Ives, C.D.; Jager, N.W. Leverage points for sustainability transformation. AMBIO J. Hum. Environ. 2017, 46, 30-39. [CrossRef]

59. Pyka, A. Transformation of economic systems: The bio-economy case. In Knowledge-Driven Developments. In The Bioeconomy: Technological and Economic Perspectives; Dabbert, S., Lewandowski, I., Weiss, J., Pyka, A., Eds.; Springer: Cham, Germany, 2017; pp. 3-16.

60. Geels, F.W. Technological Transitions and System Innovations: A Co-Evolutionary and Socio-Technical Analysis; Edward Elgar Publishing: Cheltenham, UK, 2005; ISBN 184542459X.

61. Brynjolfsson, E. The productivity paradox of information technology. Commun. ACM 1993, 36, 66-77. [CrossRef]

62. Solow, R.M. “We'd better watch out”, New York Times Book Review. The New York Times, 12 July $1987 ; 36$.

63. Kim, T.-Y.; Heshmati, A. Economic Growth: The New Perspectives for Theory and Policy; Springer Science \& Business Media: Heidelberg, Germany, 2014; ISBN 3642408265.

64. Acemoglu, D. Introduction to Modern Economic Growth; Princeton University Press: Princeton, NJ, USA, 2009; ISBN 9780691132921.

65. Acemoglu, D.; Robinson, J.A. Why Nations Fail: The Origins of Power, Prosperity, and Poverty; Currency Press: Redfern, Australia, 2013; ISBN 978-1846684302.

66. World Economic Forum. A New Way to Measure Economic Growth and Progress. Available online: https://www.weforum.org/agenda/2018/01/towards-a-new-measure-of-growth/ (accessed on 24 June 2019).

67. Gann, D.; Dodgson, M. We need to measure innovation better. Here's how. Available online: https: //www.weforum.org/agenda/2019/05/we-need-to-measure-innovation-better-heres-how-to-do-it/ (accessed on 6 May 2019).

68. Meadows, D.H. Indicators and Information Systems for Sustainable Development. Available online: http://donellameadows.org/wp-content/userfiles/IndicatorsInformation.pdf (accessed on 25 June 2019).

69. Fichter, K.; Olteanu, Y. Green Startup Monitor 2018. Available online: https://deutschestartups.org/fileadmin/ Bundesverband_Deutsche_Startups/Forschung/Green_Startup_Monitor/GreenStartupMonitor2018.pdf (accessed on 25 June 2019).

70. Umweltbundesamt. Grüne Produkte in Deutschland 2017. Marktbeobachtungen für die Umweltpolitik. Available online: https://www.umweltbundesamt.de/sites/default/files/medien/1410/publikationen/171206_uba_fb_ gruneprodukte_bf_low.pdf (accessed on 25 June 2019). 